\section{Ubiquitin and dementia}

SIR - Gallo and Anderton' draw attention to the demonstration by ubiquitin immunocytochemistry of ubiquitin-immunoreactive intraneuronal inclusions in the major neurodegenerative disorders, including Alzheimer's, Parkinson's and motor neuron diseases.

We wish to make two additional points. First, we believe that diffuse Lewy body disease can be added to Gallo and Anderton's table of common neurological diseases characterized by the presence of ubiquitinated filamentous inclusion bodies. We and others have recently shown that ubiquitin immunocytochemistry, coupled with classical neuropathological techniques, reveals diffuse Lewy body disease as a common cause of dementia ${ }^{2.4}-$ it accounts for 15-27 per cent of cases of dementia in hospital necropsies, whereas it was previously considered rare. We have also used ubiquitin immunocytochemistry to study the disorder quantitatively, and have shown that severity of dementia is related to the density of cortical inclusions but not to measures of sub-cortical pathologys.

Second, ubiquitinated filamentous inclusions are not confined to neurons but also occur in astrocytomas and, outside the nervous system, in alcoholic liver disease, a myopathy ${ }^{6}$ and in some viral diseases?. Many (but not all) of these inclusions contain intermediate filaments ${ }^{1,6}$. The significance of this last observation could relate to the cell stress or 'heatshock' response. It is well known that

\section{Silica polymorphs}

SIR-In the contents panel of Nature of 18 May 1989, an explanation of a paper ${ }^{1}$ on zeolite is accompanied by a figure that is, in fact, taken from our paper ${ }^{2}$ in the same issue on new crystal structures of silica $\left(\mathrm{SiO}_{2}\right)$. Curiously, this inadvertent association reminds us of a notion that has

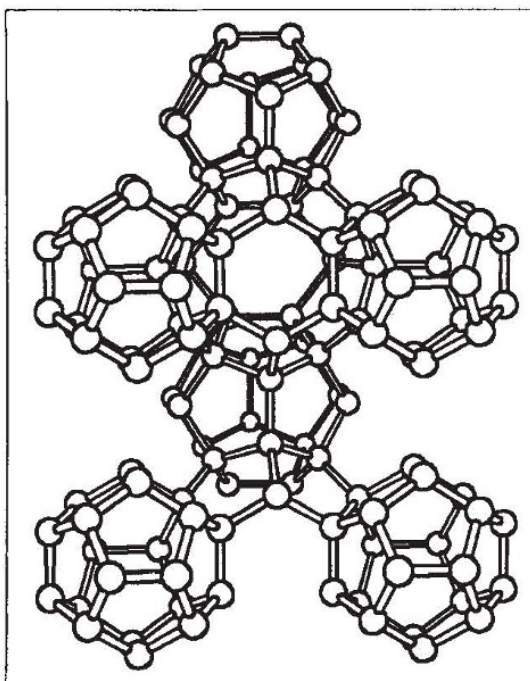
cent of zeolites. experimental chemical and thermal stresses cause specific, reversible intermediate-filament collapse in various cell types $^{8}$. We have recently shown' that the expression of a human polyubiquitin gene is increased in spinal cord and brain in motor neuron disease. Polyubiquitin genes are inducible by heat shock and are essential for cell survival ${ }^{10}$.

\section{R. J. MAYER \\ M. LANDON \\ F. J. DOHERTY}

Department of Biochemistry,

J. S. LOWE

Department of Pathology,

G. P. REYNOLDS

E. J. BYRNE

Department of Health Care of the Elderly, University of Nottingham Medical School, Nottingham NG7 2UH, UK

G. G. LENNOX

D. JEFFERSON

R. B. GODWIN-AUSTEN

Department of Neurology,

Queens Medical Centre,

Nottingham NG7 2UH, UK

1. Gallo, J.-M. \& Anderton, B.H. Nature 337, 687 (1989)

2. Lennox, G. et al. Lancet. I, 323-324 (1989)

3. Lennox, G. et al. J. Neurol. neurosurg. Psych. 52 , 67-71 (1989)

4. Perry, R. H. et al. Lancet I, 166 (1989).

5. Lennox, G. et al. in Neural Mechanisms in Disorders of Movement (eds Crossman, A.R. \& Sambrook, J.) 265268 (Libbey, London, 1989)

6. Lowe, J. et al. J. Path. 155, 9-15 (1988)

7. Mayer, R.J. et al. Biochem. Soc. Symp. 55, 193 (1989).

8. Mathews, M.B. \& Feramisco, J.R. Cold Spring Harbor Symp. quant. Biol. 46, 985-996 (1981)

9. Heggie, P. et al. Neurosci. Lett. (in the press)

10. Finley, D., Ozkaynak, E. \& Varshavsky, A. Cell 48, 1035 1046 (1989).

been at the back of our minds for some time - namely, that silica, which has typical framework structures comprising networks of tightly bound units $\left(\mathrm{SiO}_{4}\right.$ tetrahedra in this case), could assume open crystal structures that are reminis-

As an old example ${ }^{3}$, melanophlogite, which is mentioned in a standard textbook

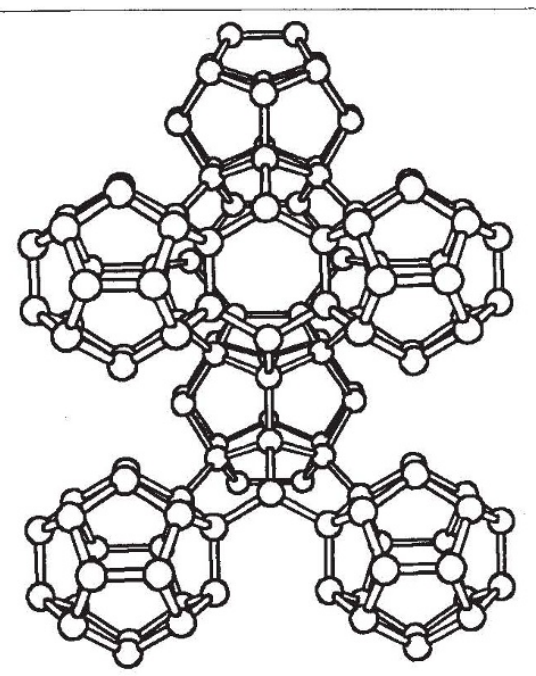

MIRAGE or no mirage?

SiR-Brenner et al. ${ }^{1}$ doubt the potential of the Mössbauer-isotope-based method of cancer therapy we described ${ }^{2}$ because of their calculation that several greys of lowenergy gamma rays would be necessary to achieve the same effect by conventional mechanisms that we achieved with $10^{-5} \mathrm{~Gy}$ of resonant Mössbauer radiation. There are three reasons for this incongruity. First, although the cross-sections are small for all atoms found in tissue, so that most of the gamma rays are absorbed by water molecules and produce random transient free radicals, the Mössbauer cross-section for ${ }^{57} \mathrm{Fe}$ (with resonant $14.4-\mathrm{keV}$ gamma rays) is about 100,000 times larger.

Considering the abundance of water molecules and ${ }^{57} \mathrm{Fe}$ atoms in these cells, and considering the cross-sections of water and ${ }^{57} \mathrm{Fe}$, we estimate that about half of the gamma photons will be absorbed by ${ }^{57} \mathrm{Fe}$ atoms. Second, the strategic position of the ${ }^{57} \mathrm{Fe}$ atoms (bonded to molecules that are intercalated in the DNA), makes absorption by ${ }^{57} \mathrm{Fe}$ atoms much more effective than absorption by random water molecules. Third, gamma-photon absorption by ${ }^{57} \mathrm{Fe}$ produces an Auger cascade, of about eight high-LET electrons, and a highly-charged iron atom, within a femtosecond. Based on our results and on the results of radiolabelling experiments with a similar mechanism, we estimate the relative cell-killing efficiency of our MIRAGE processes compared with the conventional radiotherapy processes at about $10^{5}$ to 1 .

Humm $^{3}$ points out that ${ }^{57} \mathrm{Fe}$ would only be useful for superficial lesions and has asked for a control experiment at a Doppler shift well off the Mössbauer peak. In response to the former, we observe that it would be possible to use Mössbauer isotopes with more penetrating gamma

by Wells ${ }^{4}$, is thought to have a silicon framework of chlorine hydrate structure ${ }^{5}$, as shown in the figure. Although this particular polymorph could be an impure phase of silica containing some elements such as sulphur or carbon, it serves to indicate that silica and related compounds could assume more polymorphs than currently expected.

HIDEO AOKI

SHINII TSUNEYUKI

Department of Physics,

University of Tokyo,

Hongo, Tokyo 113, Japan

Anderson, M.W. \& Klinowski, J. Nature 339, 200-203 (1989).

2. Tsuneyuki, S. et al. Nature 339, 209-211 (1989).

3. Zak, L. Amer. Mineralogist 57, 779-796 (1972).

4. Wells, A.F. Structural Inorganic Chemistry 5 th edn $\mathrm{Ch} .23$ Oxford University Press, 1984)

Pauling, L. \& Marsh, R.E. Proc. natn. Acad. Sci. U.S.A. 38 112-119 (1952) 